\title{
AVALIAÇÃO DO ÍNDICE DE DESCONFORTO TÉRMICO (IDT) EM ESCOLAS DE TEMPO INTEGRAL EM UMA CIDADE DO NORDESTE BRASILEIRO
}

\author{
Gabrielle Diniz dos SANTOS ${ }^{1}$
}

\begin{abstract}
${ }^{1}$ Bacharela em Ecologia/Universidade Federal da Paraíba (UFPB); Especialista em Planejamento Urbano e Gestão de Cidades/Centro Universitário de João Pessoa (UNIPÊ); Mestra em Desenvolvimento e Meio Ambiente (PRODEMA)/UFPB, Brasil. E-mail: gabrielledsantos90@gmail.com
\end{abstract}

Resumo. O conforto térmico é um tema de extrema importância, porém ainda de pouca relevância no meio acadêmico. Visto que as temperaturas ambientais vêm sendo atenuadas com as atividades humanas, o meio urbano também vem sendo afetado por estes fatores, devido a grande taxa de urbanização sem o devido cuidado com o ambiente em que são inseridos os elementos urbanos, sendo assim tais fatores vem causando aumento das temperaturas no meio urbano no âmbito externo e por consequência no ambiente interno, devido os elementos de cobertura do solo e das superfícies das construções. Sendo assim, este trabalho tem como objetivo a avaliação do conforto térmico em quatro escolas públicas municipais de tempo integral da cidade de João Pessoa/PB. Sendo elas Escola Municipal de Ensino Fundamental (EMEF) Conego João de Deus, EMEF Radegundis Feitosa, EMEF Ana Cristina Rolim Machado e EMEF Chico Xavier. Para a obtenção dos dados foram utilizados os termohigrômetros do tipo HOBO U-10, que foram alocados na sala mais desconfortável de cada escola analisada, os dados foram coletados durante 15 dias do período letivo do mês de Dezembro, tido como início do período seco da região. Após a obtenção dos dados, os mesmos foram processados e analisados de acordo com o índice de desconforto (IDT) de Thom e suas faixas de classificação adaptadas por Santos em 2011 para regiões de clima tropical. Os resultados mostraram que a escola com maior índice de Desconforto Térmico foi a Escola EMEF Conego João de Deus e este resultado se deu devido as configurações da sala de aula observada e do entorno bastante urbanizado. A escola com IDT mais ameno foi a escola Ana Cristina Rolim Machado e este resultado se deu devido a maior concentração de área arborizado no entorno da sala, bem como a estrutura do prédio que impede a entrada direta do sol na sala de aula. É possível afirmar também que todas as escolas demonstram altas taxas de desconforto térmico, e que está associado as configurações da sala de aula e sua localização em relação ao prédio da escola, bem como a falta de planejamento visando o clima da região para a construção de ambientes com maior eficiência energética e conforto térmico que possam favorecer o processo de aprendizado nesses ambientes.

Palavras-chave: Conforto ambiental; Ambientes de ensino; Escolas públicas. 


\section{EVALUATION OF THE THERMAL DISCHARGE INDEX COMPREHENSIVE TIME SCHOOLS IN A NORTHEAST BRAZILIAN CITY}

Abstract. The thermal comfort is a topic of extreme importance, but still has little relevance in the academic environment. Since environmental temperatures have been attenuated by human activities, the urban environment has also been affected by these factors, due to the high rate of urbanization without due care with the environment in which the urban elements are inserted, being thus such factors come causing an increase of the temperatures in the urban areas in the external environment and consequently in the internal environment, due to the elements of covering of the ground and the surfaces of the constructions. Therefore, this study aims to evaluate thermal comfort in four full-time municipal public schools in the city of João Pessoa / PB. They are Municipal School of Elementary Education (EMEF) Conego João de Deus, EMEF Radegundis Feitosa, EMEF Ana Cristina Rolim Machado and EMEF Chico Xavier. In order to obtain the data, the HOBO U-10 type thermohygrometers were used, which were allocated in the most uncomfortable room of each school analyzed, data were collected during 15 days of the December school year, considered as the beginning of the dry period of the region. After obtaining the data, they were processed and analyzed according to the Thom Discomfort Index (IDT) and their classification ranges adapted by Santos in 2011 for regions of tropical climate. The results showed that the school with the highest Thermal Discomfort index was the Conego João de Deus EMEF School and this result was due to the configurations of the observed classroom and the highly urbanized environment. The school with a milder IDT was the Ana Cristina Rolim Machado school and this result was due to the greater concentration of wooded area around the room, as well as the structure of the building that prevents the direct entry of the sun into the classroom. It is also possible to state that all schools show high rates of thermal discomfort, and that it is associated with classroom configurations and their location in relation to the school building, as well as the lack of planning aimed at the region's climate for the construction of environments with greater energy efficiency and thermal comfort that may favor the learning process in these environments.

Keywords: Environmental comfort; Teaching environments; Public schools.

\section{EVALUACIÓN DEL ÍNDICE DE DESCONFORTO TÉRMICO (IDT) EN ESCUELAS DE TIEMPO INTEGRAL EN CIUDAD DEL NORDESTE BRASILEÑO}

Resumen. El confort térmico es un tema de extrema importancia, pero todavía de poca relevancia en el medio académico. Dado que las temperaturas ambientales se han atenuado con las actividades humanas, el medio urbano también viene siendo afectado por estos factores, debido a la gran tasa de urbanización sin el debido cuidado con el ambiente en que se insertan los elementos urbanos, siendo así tales factores vienen causando aumento de las temperaturas en el medio urbano en el ámbito externo y por consecuencia en el ambiente interno, debido a los elementos de cobertura del suelo y de 
las superficies de las construcciones. Siendo así, este trabajo tiene como objetivo la evaluación del confort térmico en cuatro escuelas públicas municipales de tiempo completo de la ciudad de João Pessoa / PB. (En el caso de las mujeres), en el caso de las mujeres. Para la obtención de los datos se utilizaron los termohigrómetros del tipo HOBO U-10, que fueron asignados en la sala más incómoda de cada escuela analizada, los datos fueron recolectados durante 15 días del período lectivo del mes de diciembre, tenido como inicio del período seco de la estación seca región. Después de la obtención de los datos, los mismos fueron procesados y analizados de acuerdo con el índice de incomodidad (IDT) de Thom y sus rangos de clasificación adaptados por Santos en 2011 para regiones de clima tropical. Los resultados mostraron que la escuela con mayor índice de desconforto térmico fue la Escuela EMEF Conego João de Deus y este resultado se dio debido a las configuraciones del aula observada y del entorno bastante urbanizado. La escuela con IDT más ameno fue la escuela Ana Cristina Rolim Machado y este resultado se dio debido a la mayor concentración de área arbolada en el entorno de la sala, así como la estructura del edificio que impide la entrada directa del sol en el aula. Es posible afirmar también que todas las escuelas demuestran altas tasas de incomodidad térmica, y que está asociado las configuraciones del aula y su ubicación en relación al edificio de la escuela, así como la falta de planificación visando el clima de la región para la construcción de ambientes con mayor eficiencia energética y confort térmico que puedan favorecer el proceso de aprendizaje en esos ambientes.

Palabras clave: Confort ambiental; Entornos de enseñanza; Escuelas públicas.

\section{INTRODUÇÃO}

Atualmente muitas cidades são vistas como símbolo da crise ambiental, pois elas expressam as marcas deixadas pela ação antrópica sobre os diversos sistemas ambientais. Excesso de ruído, emissão de poluentes no ar e na água, escassez de recursos energéticos e de água, falta de tratamento adequado dos resíduos, alterações no regime de chuvas e do vento, formação de ilhas de calor e inversão térmica, são alguns dos impactos ambientais ocasionados pela ação desordenada do homem nesses ambientes (DUARTE; SERRA, 2003).

Mills et al. (2010) afirmam que a urbanização causa mudanças nos padrões da vida humana e na transformação física do espaço natural, transformando-o em espaço urbano. Sendo assim, a paisagem natural dá lugar a paisagem urbanizada, que é geralmente caracterizada pela impermeabilização do solo a qual possui propriedades térmicas e radiativas distintas. Tais transformações no uso e cobertura do solo geram mudanças no balanço de energia e na atmosfera sobrejacente, formando assim, um clima distinto nessas áreas, o chamado clima urbano. 
Os materiais de recobrimento das construções modernas nas cidades também têm contribuído para ocasionar grandes efeitos sobre o clima urbano, pois além do aumento excessivo do consumo da energia nas edificações, há também a redução das áreas verdes para dar lugar ao adensamento urbano e a verticalização as quais, sem os devidos cuidados têm gerado diversos impactos sobre o clima local.

Sendo assim, pode-se afirmar que a ação antrópica desordenada sobre o ambiente está causando interferências no campo térmico dessas áreas, com alterações que se repetem em grandes e médias cidades, e pode ser evidenciada pelo aumento da temperatura do ar, diminuição da umidade relativa e desconforto térmico, causados principalmente pela redução de áreas verdes, pela presença de concreto e asfalto, pela verticalização, e pelo aumento da atividade industrial e poluição de veículos automotores (FRANCO; NOGUEIRA, 2012).

O conforto térmico em microclimas de áreas urbanas é influenciado por uma série de parâmetros como: a geometria urbana, a vegetação, níveis de umidade e propriedade térmica dos materiais das superfícies de recobrimento (BOURBIA; BOUCHERIBA, 2009).

É diante do atual panorama de colapso ambiental dos centros urbanos, que tem sido necessário o desenvolvimento de diversos trabalhos na área da climatologia urbana, no sentido de auxiliar os planejadores ambientais na gestão sustentável desses ambientes.

No que se refere à cidade de João Pessoa, não tem sido diferente, pois mesmo sendo uma das capitais com maior índice de área verde per capita, a capital Paraibana vem sofrendo nas últimas décadas um crescimento urbano acelerado, o que tem comprometido as condições de conforto térmico da população (BATISTA et al., 2010). Sabe-se também que a arborização das cidades é uma obrigação do poder público e que por vezes acaba sendo esquecido e isso também acontece na cidade de João Pessoa.

Nesse sentido, as questões climáticas afetam também os ambientes escolares e principalmente os estudantes e professores, os quais precisam de um ambiente que apresente condições de conforto ambiental ideais para o desenvolvimento das atividades educativas realizadas diariamente. Lamberts (2011), destaca que as escolas no Brasil, principalmente as públicas, foram construídas com a preocupação do aumento da alfabetização do país em meados da década de 70, e com isso, a pouca preocupação com o conforto térmico dos alunos. As escolas foram construídas em grande quantidade e nos padrões das edificações do sul e sudeste, modelos estes adotados também no Nordeste, sem a devida preocupação com o clima regional. Essa realidade é encontrada ainda hoje, principalmente nas escolas públicas, onde a verba é limitada e este contexto não é levado em conta, já que é necessário um planejamento para a construção de prédios que atendam condições de conforto térmico. 
Para que isso ocorra, é importante que se identifique os níveis de desconforto térmico nas escolas. Pois acredita-se que as condições de conforto térmico no ambiente escolar interfiram no rendimento e comportamento dos alunos, tendo em vista que todo o espaço escolar faz parte do desenvolvimento da criança, principalmente se tratando de escolas de tempo integral, onde as crianças têm ainda mais convivência e passam mais tempo naquele ambiente (PIZARRO, 2015).

É diante desse contexto que este trabalho se apresenta com o intuito principal de verificar o Índice de Desconforto Térmico (IDT) de quatro escolas de tempo integral situadas na cidade de João Pessoa capital do estado da Paraíba. A pesquisa parte da hipótese de que as diferentes formas de uso e cobertura do solo, associadas a redução das áreas verdes e ao crescimento acelerado e desordenado da cidade de João Pessoa nas últimas décadas, afetou o campo térmico da cidade e as condições de conforto térmico de vários equipamentos públicos, dentre eles, as escolas de tempo integral.

\section{MATERIAL E MÉTODOS}

Para a realização da pesquisa foram definidas quatro escolas de tempo integral do sistema público municipal de ensino da cidade de João Pessoa. As escolas foram escolhidas em função da diferenciação das diversas formas de uso e cobertura do solo no entorno de cada uma delas. Nessas escolas foram coletados dados de temperatura e umidade relativa do ar no período seco da cidade (dezembro) no ano de 2017, visto que é o mês de início do período seco na área e sendo assim, se tem as temperaturas mais elevadas na região.

As quatro escolas estão localizadas em quatro bairros distintos da cidade (Fig. 1). A Escola Municipal de Ensino Fundamental Cônego João de Deus, está localizada no bairro Expedicionários, inserido na região leste da cidade. A Escola Municipal de Ensino Fundamental Ana Cristina Rolim Machado está localizada no bairro de Água Fria, zona sul e a Escola Municipal de Ensino Fundamental Radegundis Feitosa, no bairro do José Américo, localizado também na zona sul da cidade. E por fim, a Escola Municipal de Ensino Fundamental Chico Xavier está localizada no bairro do Bessa, área que recebe maior influência marítima. 


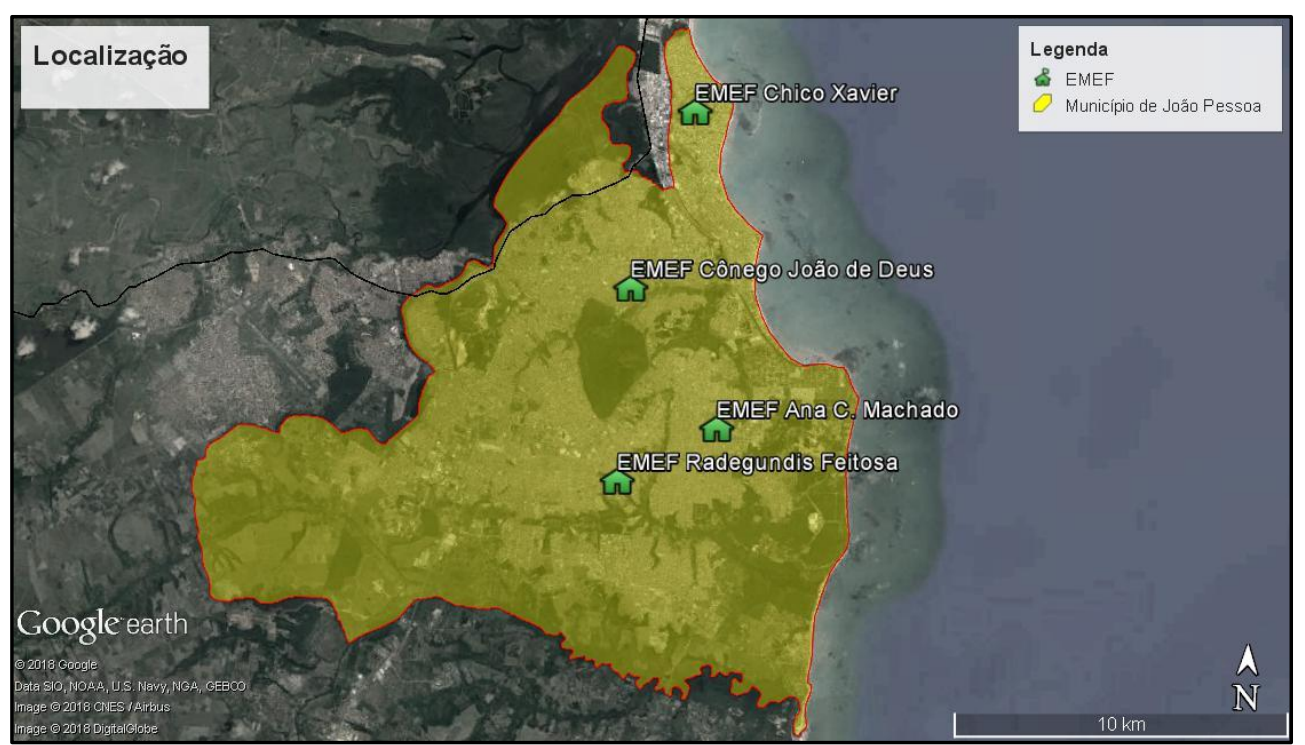

Figura 1. Localização das quatro escolas selecionadas, dentro da malha urbana de João Pessoa. Fonte: Google Earth.

Um dos fatores que definiu a escolha das escolas mencionadas foi seu funcionamento em tempo integral. As escolas foram também escolhidas devido ao seu fácil acesso para o deslocamento e segurança para a instalação dos equipamentos de medições das variáveis observadas.

\section{Procedimentos Metodológicos}

Os dados coletados nas amostras experimentais visam o monitoramento climático das variáveis: temperatura e umidade relativa do ar, pois através dessas variáveis pode-se calcular o Índice de Desconforto Térmico ambiental (IDT). As coletas dos dados ocorreram através de equipamentos termo higrômetros: Modelo HOBO U-10. Os equipamentos ficaram alocados dentro das salas de aula de cada escola para as medições diárias simultâneas. E foi escolhido dentro destas, a sala vista pelo responsável da escola, como a mais desconfortável. Para o a aferição destas variáveis, foi possível o monitoramento simultâneo de 15 dias letivos consecutivos nas quatro escolas investigadas.

Para a avaliação das condições de conforto térmico nas escolas foi utilizado o índice de Thom com suas faixas térmicas adaptados por Santos (2011). O IDT oferece uma medida razoável do grau de desconforto para várias combinações de temperatura e umidade relativa do ar, expresso em graus Celsius, e pode ser obtido pela seguinte equação:

$$
\text { IDT }=\text { T }-(0,55-0,0055 \text { UR }) \cdot(T-14,5)
$$


Onde ' $\mathrm{T}$ ' é a temperatura do $\operatorname{ar}\left({ }^{\circ} \mathrm{C}\right)$ e 'UR' é a umidade relativa do ar (\%). Na caracterização do nível de desconforto térmico, utiliza-se a classificação apresentada na tabela 1 (SANTOS, 2011).

Tabela 1. Faixa de classificação do índice de desconforto de Thom ajustado para regiões tropicais. Fonte: Santos (2011).

\begin{tabular}{c|c|c}
\hline FAIXAS & IDT $\left({ }^{\mathbf{0}} \mathbf{C}\right.$ & NÍVEL DE DESCONFORTO TÉRMICO \\
\hline $\mathbf{1}$ & IDT $<24$ & Confortável \\
\hline $\mathbf{2}$ & $24 \leq$ IDT $\leq 26$ & Parcialmente confortável \\
\hline $\mathbf{3}$ & $26<$ IDT $<28$ & Desconfortável \\
\hline $\mathbf{4}$ & IDT $\geq \mathbf{2 8}$ & Muito desconfortável \\
\hline
\end{tabular}

\section{Caracterização das amostras experimentais: escolas públicas de tempo integral}

\section{A) EMEF Cônego João e Deus}

A Escola EMEF Conego João de Deus está localizada no bairro dos Expedicionários. Bairro este, bastante urbanizado e predominantemente residencial. Percebe-se no entorno da referida escola áreas com solo pavimentado e impermeabilizado, assim como algumas manchas de solo exposto.

No interior da escola é possível verificar a presença de vegetação arbórea, solo exposto na área do parquinho das crianças, e área permeável próximo das salas de aula e também áreas impermeáveis. A escola possui 247 alunos de 5,5 a 15 anos, do $1^{\circ}$ ao $9^{\circ}$ ano do ensino fundamental.

A sala de aula escolhida para alocação do equipamento, é utilizada por turma do $4^{\circ}$ ano do ensino fundamental e possui um total de 30 alunos com idades entre 8 e 10 anos.

As salas de aula da escola foram adaptadas para receber os aparelhos de ar condicionado e nos locais de entrada de ventilação foram colocadas placas de plástico transparente (Fig. 2). As salas onde o ar condicionado funciona possui temperatura amena, já as salas onde os aparelhos não funcionam, a sensação é de muito calor, como a sala que foi escolhida para colocação do equipamento de medição de temperatura. 


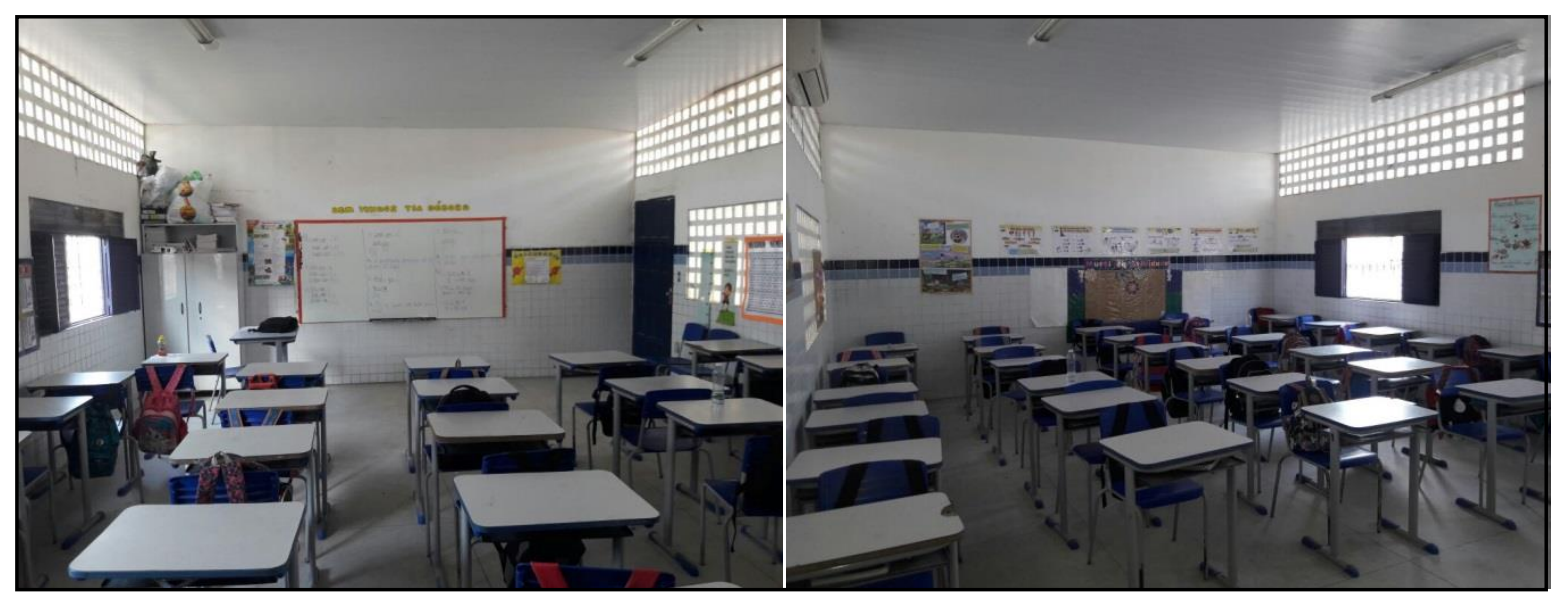

Figura 2. Sala de aula escolhida na EMEF Cônego João de Deus. Fonte: Acervo pessoal.

Como pode ser observado na imagem 3 a sala não possui sequer ventilador, apenas janelas pequenas de madeira orientadas para o sul e de frente para uma parede de concreto

\section{B) EMEF Radegundis Feitosa}

A escola Radegundis Feitosa está localizada no bairro do José Américo, que está em processo de expansão imobiliária. É uma escola de ensino fundamental durante o dia, e de ensino de jovens adultos e adolescentes durante o período da noite. A escola passou por reforma e funciona desde 2011. A sala de aula escolhida é de uma turma com um total de 25 alunos de $1^{\circ}$ ano do ensino fundamental.

No entorno da escola existe pavimento asfáltico, paralelepípedo e também uma grande área de solo exposto e vegetação arbórea. $\mathrm{Na}$ área interna de lazer da escola, existe uma quadra coberta e é realizada boa parte das atividades lúdicas com os alunos.

As salas de aula da escola são equipadas com ar condicionado, porém a maioria não funciona por falta de manutenção. No caso da sala de aula escolhida para o estudo, existe um ar condicionado e ventiladores, mas não atendem as dimensões do espaço físico da sala de aula e do número de alunos (Fig. 3). 


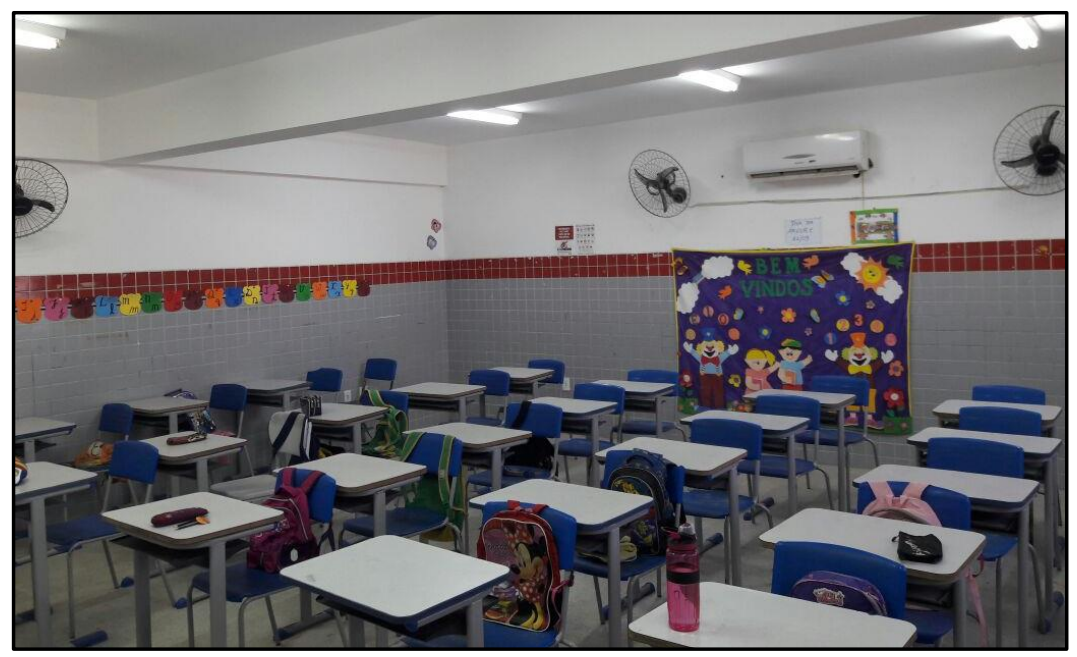

Figura 3. Sala de aula da EMEF Radegundis Feitosa. Fonte: Acervo pessoal.

No que diz respeito às características físicas, a sala investigada possui $49 \mathrm{~m}^{2}$, cobertura cerâmica até a altura de $1,70 \mathrm{~m}$ das paredes e uma grande janela onde sua largura é de $6 \mathrm{~m}$ ocupando quase toda a extensão de uma das paredes da sala e altura de 1,20m a qual está orientada para noroeste (Fig. 4).

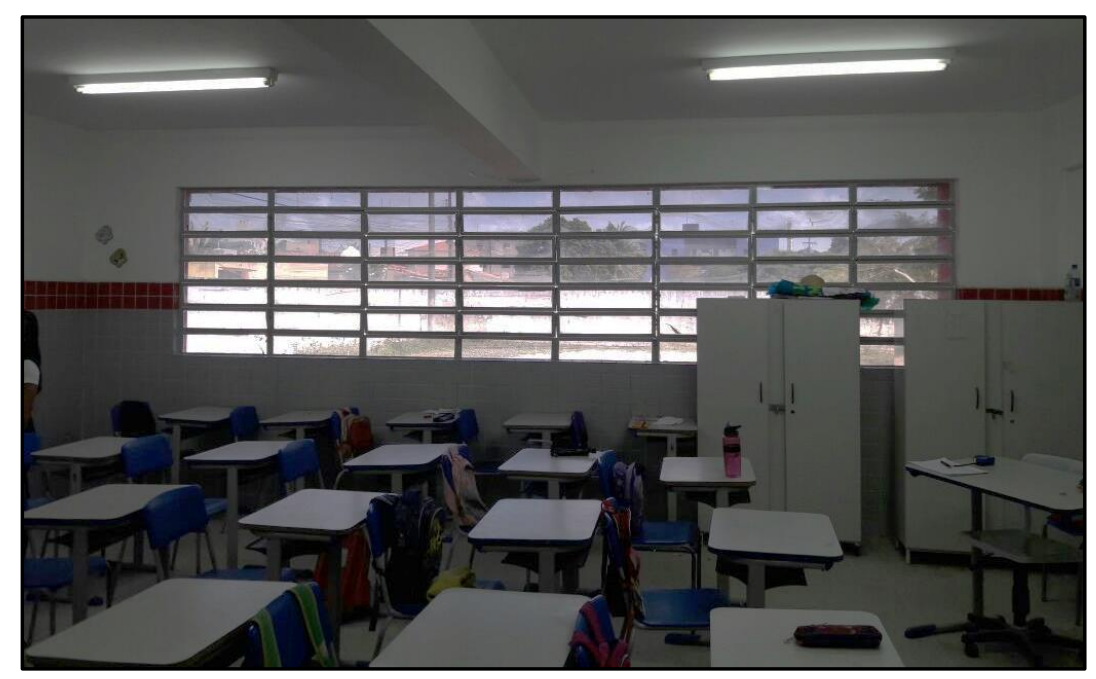

Figura 4. Sala de aula da EMEF Radegundis Feitosa. Fonte: Acervo pessoal.

Sendo assim, a orientação e formatação da janela facilita a entrada da luz do sol na sala de aula e ainda dificulta a entrada de ventilação, já que a mesma está no sentido oposto ao da direção dos ventos da região. A orientação da sala de aula possibilita que boa parte do dia o sol esteja incidindo sobre os alunos (Fig. 5). 


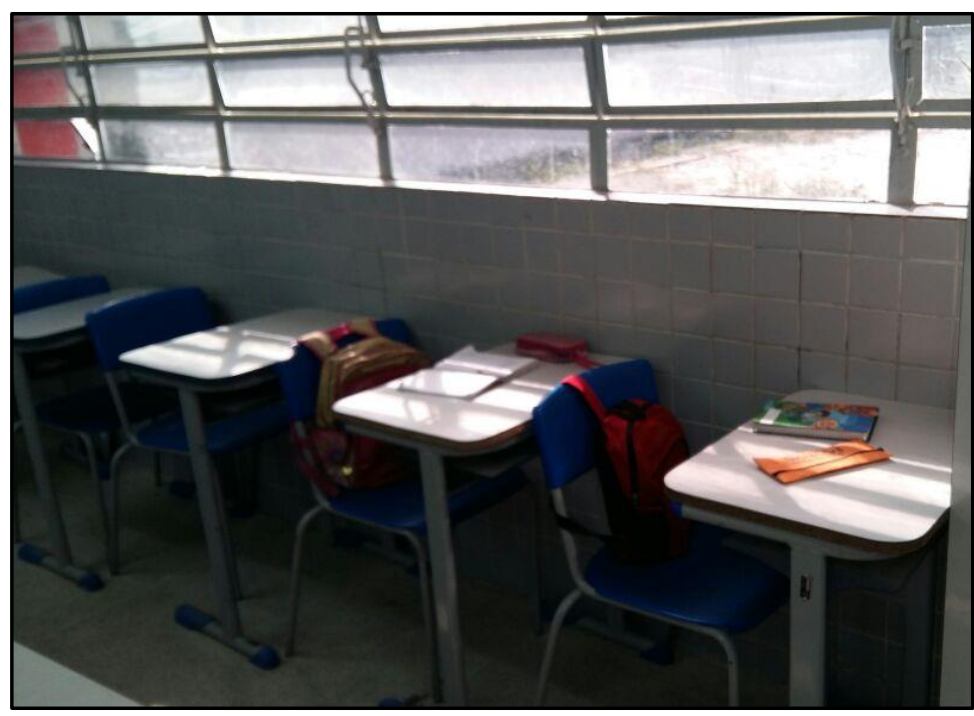

Figura 5. Sala de aula no período da tarde. Fonte: Acervo pessoal.

\section{C) EMEF Ana Cristina Rolin Machado}

A EMEF Ana Cristina Rolin Machado possui um total de 549 alunos que variam de 5 a 13 anos, do ensino infantil ao $5^{\circ}$ ano do fundamental. A sala escolhida compreende a uma turma do $4^{\circ}$ ano e possui um total de 25 alunos.

O bairro de água fria, onde se localiza a escola, é bastante especulado pelo setor imobiliário, tendo assim, grande porcentagem de cobertura impermeável e reduzido número de áreas verdes. $\mathrm{O}$ entorno da escola é composto por área com cobertura vegetal, solo exposto e também área pavimentada.

As salas de aula possuem ventilador e janelas, mas a maioria permanece fechada. $\mathrm{O}$ local onde a escola funciona é um prédio alugado pela prefeitura da cidade, portanto não pode sofrer muitas alterações em sua estrutura. Dentre as escolas investigadas, essa é a que não tem estrutura moderna quando comparada com as outras escolas. No entanto, essa também é a escola que apresenta a maior área verde do entorno em relação as demais.

A sala de aula avaliada mede $32 \mathrm{~m}^{2}$ e não possui climatização artificial. Apesar de ter sido instalada a fiação para receber ar condicionados, a mesma não possui carga elétrica para a alocação dos aparelhos, característica dada por ser um prédio antigo e com pouca manutenção.

A sala escolhida possui apenas uma janela de madeira, a qual nem sempre está aberta, para evitar a entrada de insetos já que fica voltada para uma área com vegetação. E quando fechada, impede uma melhor ventilação da sala, sendo necessário o uso de ventiladores, os quais amenizam as altas temperaturas (Fig. 6). Porém, a mesma só tem um ventilador para a sala toda o que não é suficiente. 


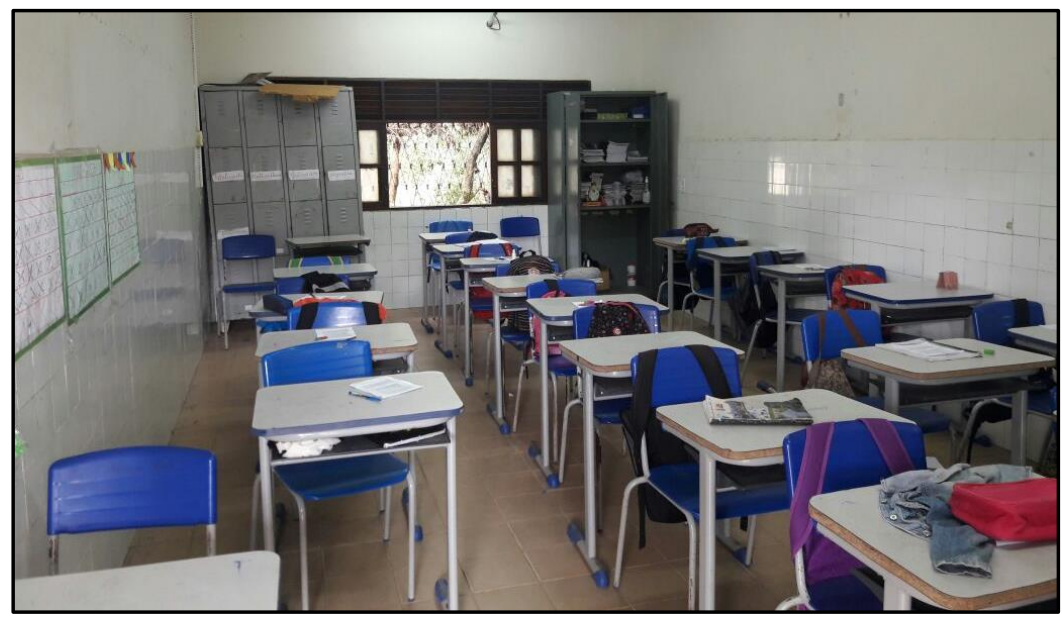

Figura 6. Sala de aula avaliada da EMEF Ana Cristina Machado. Fonte: Acervo pessoal.

\section{D) EMEF Chico Xavier}

A escola EMEF Chico Xavier está localizada no bairro Jardim Oceania, na zona leste de João Pessoa, tem em seu entorno solo exposto, pavimentado com asfalto e também a presença de vegetação. Outra característica que deve ser levada em consideração é sua proximidade com o mar. A área em que está localizada a referida escola tem sido bastante utilizada pelo mercado imobiliário, e assim, a cobertura vegetal vem sendo reduzida a cada dia e o bairro se verticalizando.

A escola possui em média 300 alunos do ensino fundamental II, nas faixas etárias de 11 a 18 anos de idade e também funciona durante a noite para jovens e adultos que querem finalizar o ensino médio. As áreas de lazer da escola são compostas por áreas cobertas e expostas ao sol. O interior da escola possui apenas uma árvore, uma parte de solo exposto e outra área com solo de recobrimento granítico.

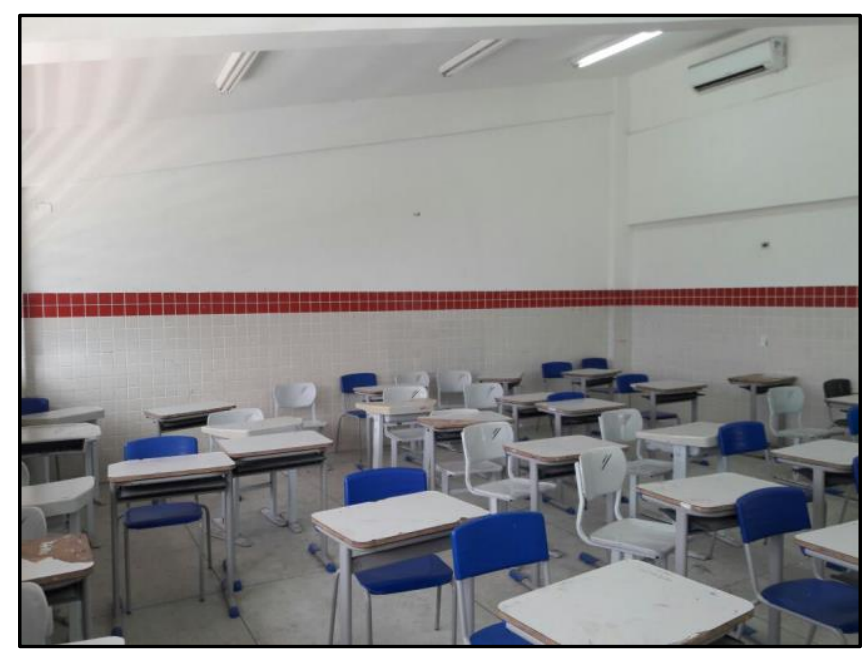

Figura 7. Sala de aula da EMEF Chico Xavier. Fonte: Acervo pessoal. 
As salas de aula são equipadas com aparelhos de ar condicionado, porém em algumas salas estes se encontram sem funcionar. As salas possuem uma janela grande de vidro que permite a entrada da luz do sol o dia inteiro (Fig. 8). Observou-se na escola salas de aulas os aparelhos de ar condicionado não funcionam e nem possuem ventilador (Fig. 7). Nesse caso, a ventilação dentro delas fica sujeita à posição dos ventos na região.

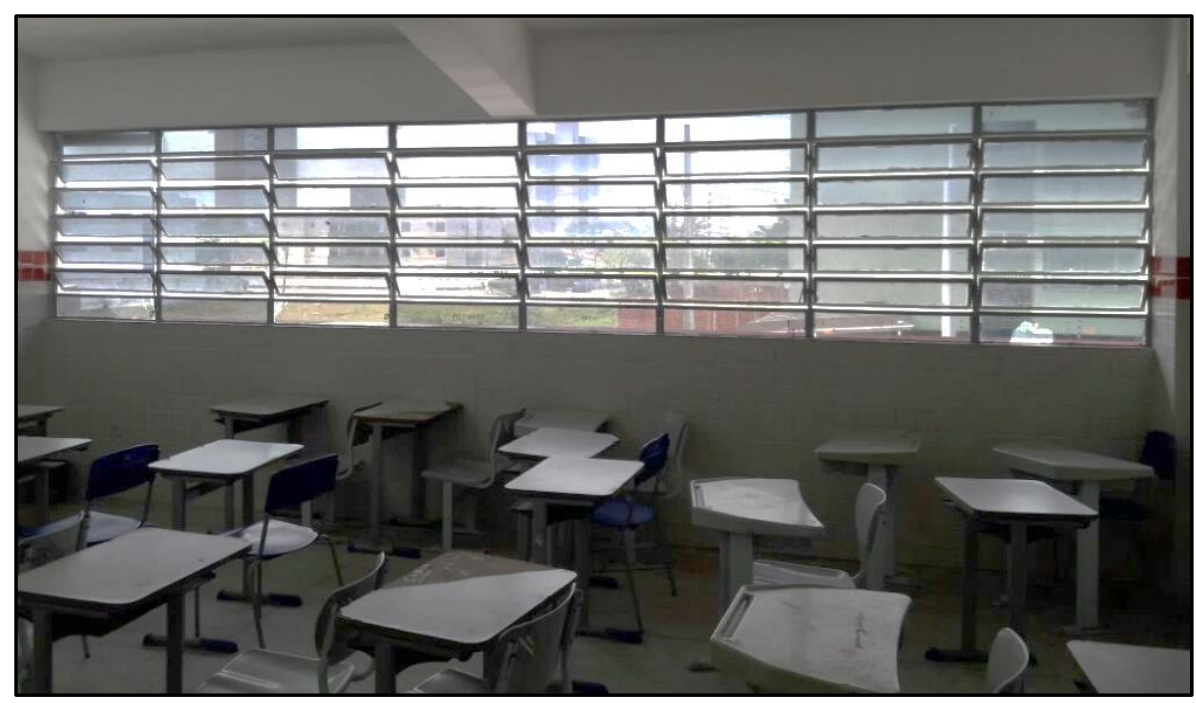

Figura 8. Janela da sala de aula avaliada da EMEF Chico Xavier. Fonte: Acervo pessoal.

A sala avaliada possui $58,42 \mathrm{~m}^{2}$ e a janela fica orientada para sudeste, ou seja, para a direção dos ventos na região durante a maior parte do ano. A janela é transparente o que garante a grande entrada de iluminação durante todo o dia. A mesma possui dois aparelhos de ar condicionado, porém não estão funcionando. A sala possui coloração clara e até a altura de $1,67 \mathrm{~m}$ possui recobrimento cerâmico nas cores cinza e vermelho (figura 8).

Um ponto interessante observado nas escolas, é que três destas possuem ar condicionado que não funcionam ou não sofrem manutenção regular. Isso demonstra que não foram aproveitados elementos da bioclimatologia local visando o aproveitamento da circulação do ar e iluminação natural na construção dos prédios.

Todas as escolas citadas, são de ensino integral do nível fundamental. Ou seja, as crianças passam o dia nesses ambientes no horário que corresponde entre às 07:00 e 17:00 horas.

\section{RESULTADOS E DISCUSSÃO}

Avaliação do Índice de conforto térmico nas escolas investigadas durante o período seco 


\section{A) AVALIAÇÃO DO IDT NA ESCOLA EMEF CÔNEGO JOÃO DE DEUS}

Esta escola foi caracterizada com altos IDTs durante todos os dias letivos avaliados, e devido a esses valores, as classificações se mantiveram entre desconfortável e muito desconfortável (faixas 3 e 4) segundo o índice de desconforto de Thom adaptado para regiões tropicais por Santos (2011). Observando o monitoramento das variáveis na sala de aula desta escola percebe-se que o menor IDT foi encontrado no dia 6 do mês de Dezembro medindo $26,5^{\circ} \mathrm{C}$. Esse IDT foi classificado na faixa 3 como desconfortável. Já o dia que apresentou as piores condições de conforto térmico foi o dia 15 no mesmo mês apresentando um IDT de $28,4^{\circ} \mathrm{C}$ classificado como desconfortável. Os valores do IDT podem ser observados na tabela abaixo (Tab. 2):

Tabela 2. IDT no sentido diário da EMEF Cônego João de Deus.

\begin{tabular}{ccc}
\hline Dias letivos & IDT $\left({ }^{\circ} \mathrm{C}\right)$ & Faixa de classificação \\
\hline $\mathbf{1}$ & 27,6 & Desconfortável \\
\hline $\mathbf{2}$ & 27 & Desconfortável \\
\hline $\mathbf{3}$ & 27,5 & Desconfortável \\
\hline $\mathbf{4}$ & 27,3 & Desconfortável \\
\hline $\mathbf{5}$ & 27,8 & Desconfortável \\
\hline $\mathbf{6}$ & 26,5 & Desconfortável \\
\hline $\mathbf{7}$ & 27 & Desconfortável \\
\hline $\mathbf{8}$ & 27,9 & Desconfortável \\
\hline $\mathbf{9}$ & 28 & Desconfortável \\
\hline $\mathbf{1 0}$ & 28,1 & Muito desconfortável \\
\hline $\mathbf{1 1}$ & 27,7 & Desconfortável \\
\hline $\mathbf{1 2}$ & 27,6 & Desconfortável \\
\hline $\mathbf{1 3}$ & 27,5 & Desconfortável \\
\hline $\mathbf{1 4}$ & 28,2 & Muito desconfortável \\
\hline $\mathbf{1 5}$ & 28,4 & Muito desconfortável \\
\hline Média & 27,6 & Desconfortável \\
\hline
\end{tabular}

A média do IDT registrado nesta sala de aula foi de $27,6^{\circ} \mathrm{C}$ que não diferente das médias diárias. Tal média ficou enquadrada na faixa 3 da classificação de Thom, ou seja, desconfortável. 
Pode-se observar na tabela 2 que todos os dias se mantiveram com altas temperaturas, porém, três dias se destacaram por terem apresentado as maiores médias do período investigado, os quais se enquadraram na faixa 4 do índice de Thom considerado desconfortável. Tais dias foram: o dia 10 com IDT $28,1^{\circ} \mathrm{C}$; O dia 14 com IDT $28,1^{\circ} \mathrm{C}$, e o dia 15 com IDT $28,4^{\circ} \mathrm{C}$. Tal fato, pode estar atrelado às altas temperaturas desse período nessa região, o que potencializa a sensação de desconforto térmico ambiental. Santos (2011) encontrou resultados semelhantes ao investigar as condições do campo térmico urbano da cidade de João Pessoa/PB.

A sala de aula verificada, apresenta configuração arquitetônica que favorece as altas temperaturas e a sensação de desconforto térmico, pois as janelas são desproporcionais ao tamanho da sala e falta aberturas ao longo da sala para garantir a circulação do ar. Fatores como baixa ventilação e maior incidência solar, contribuem para as altas taxas de temperatura e assim um maior índice de desconforto térmico (LENGEN, 2004; PAULA, 2004; SHAMS et al., 2009).

\section{B) AVALIAÇÃO DO IDT NA ESCOLA EMEF RADEGUNDIS FEITOSA}

De acordo com as medições realizadas nesta escola e posterior cálculo dos índices de conforto térmico, pode-se observar que todos os dias analisados tiveram IDT enquadrado na faixa 3 do índice de desconforto de Thom, ou seja, desconfortável. Em nenhum dos dias monitorados foi encontrado o registro de IDTs confortável ou parcialmente confortável. Durante este período, as médias de temperatura registradas foram bem elevadas o que potencializou as condições termais adversas (Tab. 3). Alunos e professores sofrem para desenvolver suas atividades educacionais em sala de aula.

Tabela 3. IDT no sentido diário da EMEF Radegundis Feitosa.

\begin{tabular}{ccc}
\hline Dias Letivos & IDT $\left({ }^{\circ} \mathrm{C}\right)$ & Faixa de classificação \\
\hline $\mathbf{1}$ & 27,5 & Desconfortável \\
\hline $\mathbf{2}$ & 26,5 & Desconfortável \\
\hline $\mathbf{3}$ & 27,4 & Desconfortável \\
\hline $\mathbf{4}$ & 27 & Desconfortável \\
\hline $\mathbf{5}$ & 26,4 & Desconfortável \\
\hline $\mathbf{6}$ & 26,3 & Desconfortável \\
\hline $\mathbf{7}$ & 27,2 & Desconfortável \\
\hline
\end{tabular}




\begin{tabular}{ccc}
\hline $\mathbf{8}$ & 27,6 & Desconfortável \\
\hline $\mathbf{9}$ & 27,7 & Desconfortável \\
\hline $\mathbf{1 0}$ & 27,9 & Desconfortável \\
\hline $\mathbf{1 1}$ & 27,4 & Desconfortável \\
\hline $\mathbf{1 2}$ & 27,5 & Desconfortável \\
\hline $\mathbf{1 3}$ & 27 & Desconfortável \\
\hline $\mathbf{1 4}$ & 27,3 & Desconfortável \\
\hline $\mathbf{1 5}$ & 28 & Desconfortável \\
\hline Média & 27,2 & Desconfortável \\
\hline
\end{tabular}

Dentre os valores observados na tabela 3, nota-se que o dia com maior média de IDT foi o dia 15 que registrou $28^{\circ} \mathrm{C}$. Isso é um fator bastante preocupante, pois, além deste dia, os demais dias monitorados se enquadraram nesta mesma faixa de classificação. Vale salientar, que até mesmo o dia 6 , o qual corresponde, ao dia com menor IDT apresentou $26,3^{\circ} \mathrm{C}$. A média de IDT dos 15 dias para esta escola foi de $27,2^{\circ} \mathrm{C}$, o que se caracteriza condições termicamente desconfortáveis.

Assim como a Escola Cônego João de Deus, a sala de aula avaliada apresentou características arquitetônicas que não condizem com as condições do clima local. A sala apresenta alta incidência solar ao longo do dia, janela com configuração e posição desfavoráveis e - para esta sala - ar condicionado de pequeno porte para o tamanho da sala, que neste caso não é suficiente para garantir as condições de salubridade do ambiente.

\section{C) AVALIAÇÃO DO IDT NA ESCOLA EMEF ANA CRISTINA ROLIM MACHADO}

Durante o período seco avaliado a escola Ana Cristina Rolim Machado assim como as demais, apresentou IDT desconfortável em todos os dias do período de medições (Tab. 4). Neste contexto, pode-se afirmar que o dia com as menores médias de IDT foi o dia 5, com média de $26,1^{\circ} \mathrm{C}$, ainda assim, enquadrado na faixa 3 (desconfortável). Os dias com as maiores médias registradas de IDT foram os dias 3 e 15 com $27,2^{\circ} \mathrm{C}$ tido como desconfortável.

Tabela 4. IDT no sentido diário na EMEF Ana Cristina Rolim Machado.

\begin{tabular}{ccc}
\hline Dias Letivos & IDT $\left({ }^{\circ} \mathrm{C}\right)$ & Faixa de classificação \\
\hline $\mathbf{1}$ & 27,1 & Desconfortável \\
\hline
\end{tabular}




\begin{tabular}{ccc}
\hline $\mathbf{2}$ & 26,8 & Desconfortável \\
\hline $\mathbf{3}$ & 27,2 & Desconfortável \\
\hline $\mathbf{4}$ & 26,9 & Desconfortável \\
\hline $\mathbf{5}$ & 26,1 & Desconfortável \\
\hline $\mathbf{6}$ & 26,5 & Desconfortável \\
\hline $\mathbf{7}$ & 27 & Desconfortável \\
\hline $\mathbf{8}$ & 27 & Desconfortável \\
\hline $\mathbf{9}$ & 26,8 & Desconfortável \\
\hline $\mathbf{1 0}$ & 27 & Desconfortável \\
\hline $\mathbf{1 1}$ & 26,9 & Desconfortável \\
\hline $\mathbf{1 2}$ & 27 & Desconfortável \\
\hline $\mathbf{1 3}$ & 26,6 & Desconfortável \\
\hline $\mathbf{1 4}$ & 27 & Desconfortável \\
\hline $\mathbf{1 5}$ & 27,2 & Desconfortável \\
\hline Média & 26,8 & Desconfortável \\
\hline
\end{tabular}

A média de temperatura dos 15 dias foi de $26,8^{\circ} \mathrm{C}$ para esta escola, caracterizada como desconfortável. Este resultado indica que a sala de aula se torna um ambiente insalubre para a realização de atividades de cunho intelectual, baseado no fato de que durante todos os dias de medição, as médias de temperatura foram bastante elevadas, garantindo assim, altas médias de índice de desconforto térmico.

Outro fator a ser levado em consideração em praticamente todas as escolas são as características do entorno das salas de aulas, pois apresentam reduzida cobertura vegetal, impermeabilização e padrões arquitetônicos não condizentes com a realidade climática da área de estudo. Tais características são fatores agravantes que potencializam as condições de desconforto térmico ambiental.

Lengen (2004) sugere que em ambientes de clima tropical as construções tenham estrutura que evitem alta exposição solar nas paredes mais longas, beirais extensos que façam sombra, telhado grande para dissipar o calor ou pintado de branco que proporciona a refletância dos raios solares. $\mathrm{O}$ autor sugere também, que se evite superfícies que refletem a luz solar próximas à construção e proteção das áreas externas com vegetação, pois a mesma mantém o ar mais fresco devido seus processos metabólicos. Estas ferramentas auxiliam na garantia de ambientes mais confortáveis e ainda garantem uma maior eficiência energética. 


\section{D) AVALIAÇÃO DO IDT NA ESCOLA EMEF CHICO XAVIER}

Esta escola, assim como as demais, teve altos IDTs durante todos os dias de monitoramento variando de desconfortável a muito desconfortável.

Na tabela 5 é possível observar os dias que ocorreram os menores IDTs e os dias que apresentaram as maiores taxas de desconforto térmico. A média registrada para o período monitorado foi de $27,3^{\circ} \mathrm{C}$ (desconfortável).

Tabela 5. IDT no sentido diário da EMEF Chico Xavier.

\begin{tabular}{ccc}
\hline Dias Letivos & IDT $\left({ }^{\circ} \mathrm{C}\right)$ & Faixa de classificação \\
\hline $\mathbf{1}$ & 27,8 & Desconfortável \\
\hline $\mathbf{2}$ & 26,6 & Desconfortável \\
\hline $\mathbf{3}$ & 26,6 & Desconfortável \\
\hline $\mathbf{4}$ & 27,1 & Desconfortável \\
\hline $\mathbf{5}$ & 26,7 & Desconfortável \\
\hline $\mathbf{6}$ & 26,6 & Desconfortável \\
\hline $\mathbf{7}$ & 26,8 & Desconfortável \\
\hline $\mathbf{8}$ & 27,4 & Desconfortável \\
\hline $\mathbf{9}$ & 27,5 & Desconfortável \\
\hline $\mathbf{1 0}$ & 27,7 & Desconfortável \\
\hline $\mathbf{1 1}$ & 27,5 & Desconfortável \\
\hline $\mathbf{1 2}$ & 27,3 & Desconfortável \\
\hline $\mathbf{1 3}$ & 27,4 & Desconfortável \\
\hline $\mathbf{1 4}$ & 28,1 & Muito desconfortável \\
\hline $\mathbf{1 5}$ & 27,8 & Desconfortável \\
\hline Média & 27,3 & Desconfortável \\
\hline
\end{tabular}

Estes resultados estão associados ao fato de que a sala de aula possui configuração que não favorece o conforto ambiental. Sendo um deles, a configuração da janela, que mesmo sendo grande, seu formato não garante uma boa entrada de ventos. Vale destacar, que existe uma única janela nesta sala de aula. Em consonância com o tema, Holanda (1976) sugere que em regiões de clima tropical como no nordeste brasileiro, a otimização climática dos ambientes internos pode ser realizada utilizando estruturas arquitetônicas nas construções, 
como por exemplo os "combogós", "quebras-sol", o peitoril ventilado ou até mesmo portas mais largas ou vazadas que permitam a entrada e circulação dos ventos. Estes poderiam ser utilizados também nas outras escolas investigadas, pois otimizariam a eficiência energética e ainda garantiriam um ambiente mais confortável.

Mesmo a escola estando localizada em uma área litorânea apresentou condições de insalubridade e desconforto térmico ambiental. Santos (2011) corrobora tais resultados ao destacar bairros situados na área litorânea de João Pessoa/PB com maiores IDTs e ilhas de calor durante o período seco na região. Afirma o referido autor, que os materiais de recobrimento do entorno de cada ponto monitorado exerceu maiores influências no campo térmico urbano da cidade.

A área ao redor da escola é bastante especulada economicamente o que leva a uma grande construção de prédios altos de forma que impede a entrada da ventilação para o continente e acaba aumentando as temperaturas nas zonas urbanas pela falta de circulação do ar. Os arredores desta escola são bastante urbanizados e este pode ser um fator que contribui para o aumento da temperatura nesta área.

\section{Análise Comparativa do IDT nas Quatro Escolas Investigadas no período seco}

Durante o monitoramento dos 15 dias do período seco verificou-se que todas as escolas apresentaram IDT variando de Desconfortável a Muito Desconfortável.

As médias gerais do IDT durante os 15 dias monitorados em cada escola foram de $27,6^{\circ} \mathrm{C}$ na escola Conego João de Deus, $27,2^{\circ} \mathrm{C}$ na escola Redegundis Feitosa, $26,8^{\circ} \mathrm{C}$ na escola Ana Cristina Rolim Machado e $27,3^{\circ} \mathrm{C}$ na escola Chico Xavier, todas médias enquadradas na faixa 3 do índice de Thom (desconfortável).

Observou-se que o dia quinto dia de medições apresentou as menores taxas de IDT em todas as escolas monitoradas: $27,8^{\circ} \mathrm{C}$ na escola Cônego João de Deus; $26,7^{\circ} \mathrm{C}$ na escola Chico Xavier; $26,4^{\circ} \mathrm{C}$ na escola Radegundis Feitosa e $26,1^{\circ} \mathrm{C}$ na Escola Ana Cristina Rolim Machado, sendo esta última, a menor média encontrada neste dia (Fig. 9).

Os dias que demonstraram os piores índices de desconforto térmico foram o décimo e décimo quinto dias. No décimo dia a escola com maior IDT encontrado foi a escola Conego João de Deus, com valor de $28,1^{\circ} \mathrm{C}$ (muito desconfortável), em seguida a escola Radegundis Feitosa medindo $27,9^{\circ} \mathrm{C}$ (desconfortável), logo após esta, a escola Chico Xavier com $27,7^{\circ} \mathrm{C}$ (desconfortável) e por último a escola Ana Cristina com $27^{\circ} \mathrm{C}$ (desconfortável). 


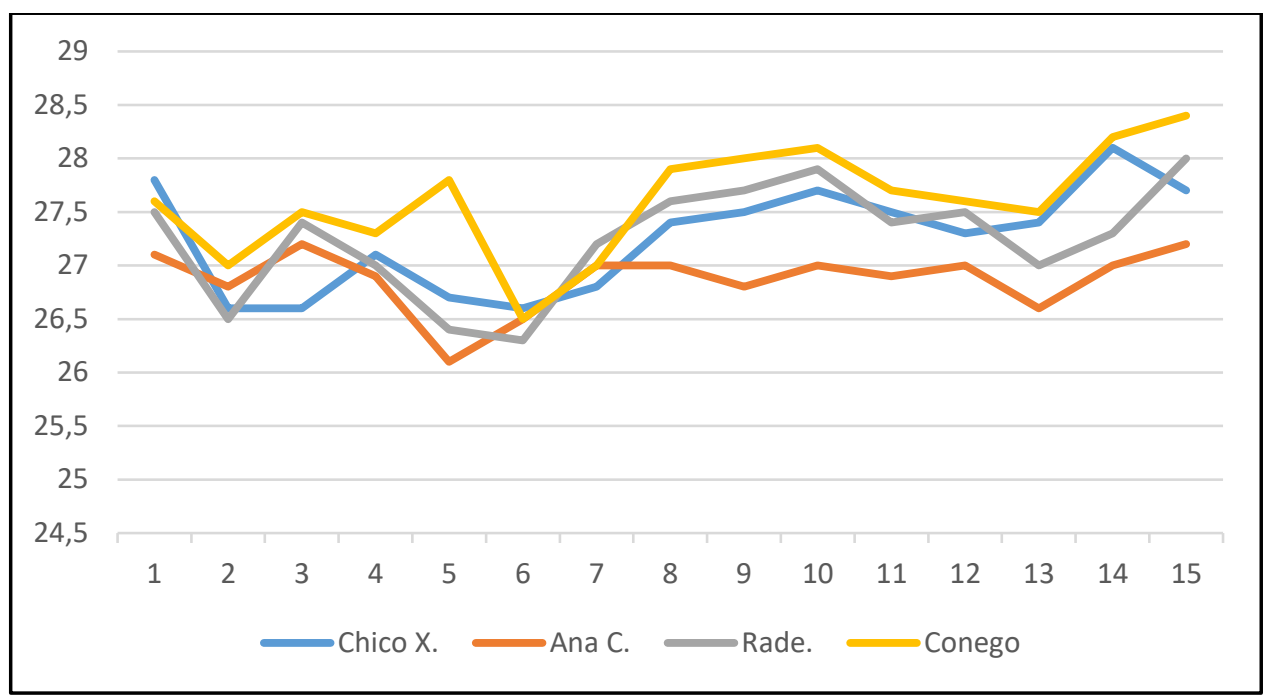

Figura 9. IDT comparativo das quatro escolas.

As altas taxas de IDT se repetiram no dia décimo quinto dia: $28,4^{\circ} \mathrm{C}$ na escola Cônego João de Deus, valor caracterizado como muito desconfortável; $28^{\circ} \mathrm{C}$ na escola Radegundis Feitosa, enquadrado como desconfortável; $27,7^{\circ} \mathrm{C}$ na Escola Chico Xavier enquadrado na faixa 3 (desconfortável) e $27,2^{\circ} \mathrm{C}$ na escola Ana Cristina Rolim Machado classificado como desconfortável (Fig. 9).

Diante destes resultados é possível afirmar que a escola com maior IDT durante a maior parte dos dias foi a Conego João de Deus. Este fato está associado a configuração da sala de aula, onde as janelas mesmo estando favoráveis à posição dos ventos, são pequenas, as entradas de ventilação que poderiam ajudar na climatização natural através dos ventos foram bloqueadas para colocar ar condicionado, a sala fica separada do bloco principal da escola, o que permite uma maior exposição das paredes externas à radiação solar durante o dia sendo estes fatores determinantes para a alta insalubridade desta sala de aula, e tornando estes resultados de extrema importância para a tomada de decisões relativas à saúde e conforto dos professores e alunos que estão expostos as altas taxas de desconforto encontradas aqui.

Dentre as escolas monitoradas, a escola com menores índices de desconforto térmico foi a escola Ana Cristina. Este fato pode estar associado ao seu entorno, que dentre as quatro escolas, é a que apresenta maior quantidade de cobertura vegetal. As demais escolas se encontram em centros urbanos bastante construídos com reduzida cobertura vegetal e maior área impermeabilizada. Dessa forma, verifica-se o papel e importância da cobertura vegetal do entorno na amenização climática. 


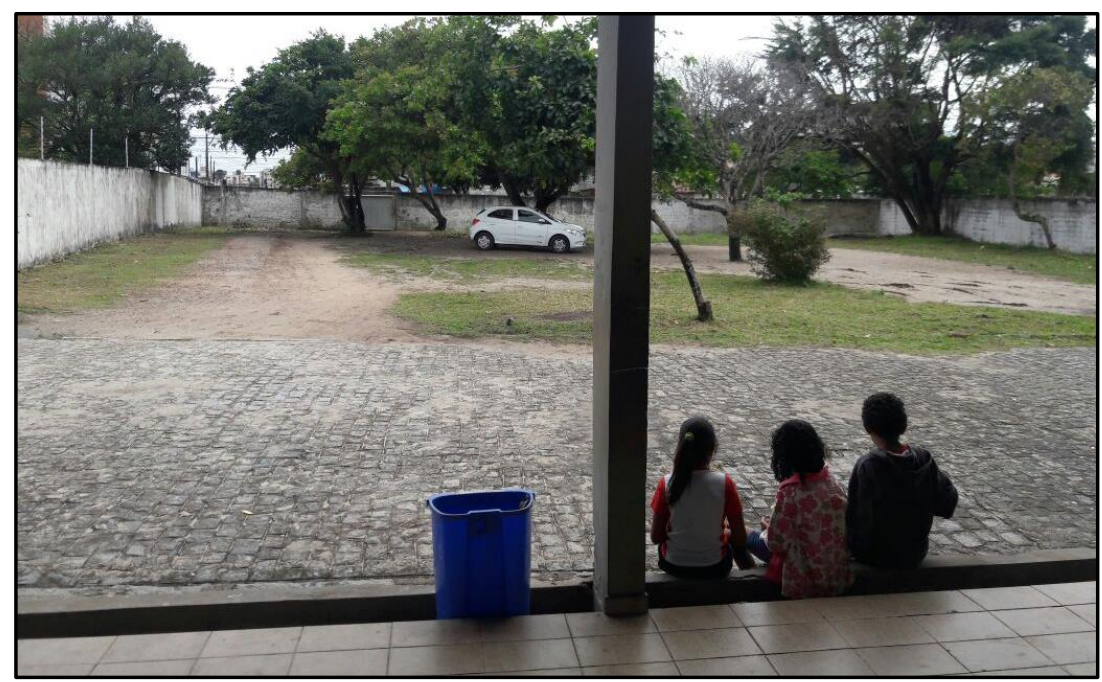

Figura 10. Área externa da sala de aula na EMEF Ana Cristina Rolim Machado. Fonte: Arquivo pessoal.

Um outro fator que influenciou neste aspecto é a localização da sala no prédio da escola, como pode ser observado na figura 10. Observa-se que em frente a sala de aula existe um corredor coberto que gera sombra e não permite a entrada direta do sol no ambiente e isto acaba atenuando a temperatura no entorno e interior da sala de aula. Este tipo de arquitetura é exemplificada na figura 11 (varanda corrida) e é tida como algo simples e de vasto uso nas construções do nordeste, a qual foi bastante explorada durante o século XIX, visando gerar sombra em áreas que devido sua posição no prédio, permanecem expostas a radiação solar durante maior parte do dia (HOLANDA, 1976).

Lembrando que, estes fatores apenas amenizaram as temperaturas nesta sala de aula avaliada, pois, ainda assim, este ponto apresentou alto índice de desconforto térmico.

Na escola Radegundis Feitosa, é possível também observar altas taxas de IDT em todos os dias observados, e sua maior média, encontrada no dia 15 medindo $28^{\circ} \mathrm{C}$, sendo fundamental lembrar que esta sala de aula possui ar condicionado funcionando e que este deveria amenizar a temperatura do ambiente, e se torna insuficiente por sua capacidade em relação ao tamanho da sala de aula. 


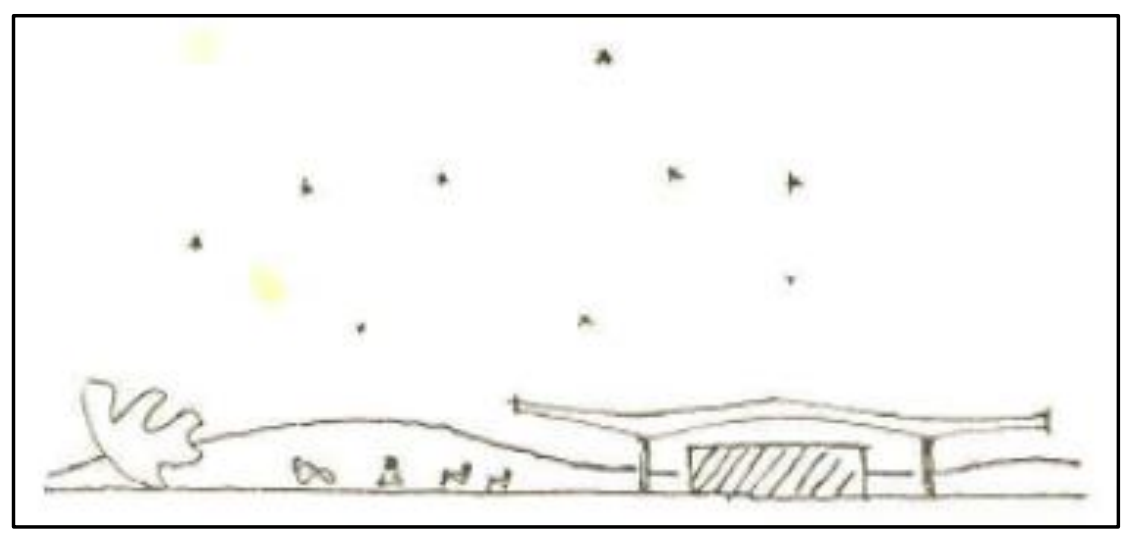

Figura 11. Exemplo de varanda corrida. Fonte: Adaptado de Holanda (1976).

A escola Chico Xavier, também apresentou resultados semelhantes e neste caso, estão associados às configurações da janela e à falta de outras aberturas para a melhor circulação do ar, já que a sala não possui climatização artificial, esta seria uma solução. Esta escola é situada em um bairro litorâneo e poderia ter sido construída em função das brisas marinhas, assim poderia ter sido potencializado os fatores de conforto ambiental e economia energética do prédio.

Nesse contexto pode-se afirmar que a ventilação propicia além da sensação de bemestar, a maior taxa de troca de calor do corpo com o ambiente, permitindo assim o conforto térmico, por isso, este fator é de extrema importância para a garantia da salubridade ambiental e que pode ser explorado principalmente durante o período seco, que tem naturalmente como característica o aumento das temperaturas (RUAS; LABAKI, 2001).

Diante disto, cabe destacar ainda que todas as escolas apresentaram IDT acima de $26^{\circ} \mathrm{C}$, fator que confirma que em nenhum dia deste período as quatro escolas apresentaram médias entre as classificações de confortável ou parcialmente confortável no índice de desconforto de Thom com faixas de classificação adaptadas por Santos (2011) para regiões tropicais. Afirmando que os resultados são preocupantes para a realização das atividades de cunho intelectual, de forma que as altas temperaturas podem interferir diretamente nas atividades tanto dos alunos como dos professores e podem também afetar a saúde destes indivíduos.

Outro fator que vale destaque é que as escolas Radegundis Feitosa e Chico Xavier foram reformadas visando maior conforto dos alunos, em todas as salas do prédio foram colocados aparelhos de ar condicionado, porém, assim como as salas observadas, as demais salas ou os aparelhos não funcionam ou não passam por constantes manutenções, o que compromete o uso e eficiência desses aparelhos. Outro fato a ser comentado é que o prédio foi 
construído para que dependessem dos aparelhos de ar condicionado e por isso, as salas onde estes não funcionam, se mantêm com altas temperaturas.

As Escolas Ana Cristina Rolim Machado e Conego João de Deus, estão implantadas em prédios que não sofreram reforma, e assim passaram apenas por adaptações das salas para que fosse colocado ar condicionado nestes ambientes. Na escola Conego, é relatado que os aparelhos funcionam bem em algumas salas, porém em outras, eles nem funcionam, como é o caso da sala observada, a qual foi adaptada para este, porém acabou sendo prejudicada.

A escola Ana Cristina, não possui ar condicionado nas salas, pois a carga de energia não suporta a instalação destes aparelhos que seriam paliativos, assim os agentes de conforto térmico passam a ser garantidos pela ventilação externa e pela utilização de ventiladores que por vezes nem funcionam mais.

Sendo assim, todos estes fatores citados acabam por ser agravantes das temperaturas no período seco em todas as escolas.

Mesmo sabendo que o conforto térmico é "o estado mental que expressa a satisfação do homem com o ambiente térmico que o circunda" (LAMBERTS et al, 2005 p. 5), é possível estimar o conforto térmico através dos índices de conforto humano, ou através de questionários, podendo assim, buscar sempre ambientes mais agradáveis ao convívio humano e como consequência, um melhor aproveitamento energético. Dessa forma, fica claro na pesquisa que as salas de aula avaliadas podem ser consideradas ambientes insalubres para professores e alunos.

De acordo com Batiz et al. (2009), as altas temperaturas em ambientes que são realizadas atividades sedentárias, podem causar diversos efeitos ao corpo, dentre eles dor de cabeça, fadiga, sono, descoordenação motora e perda de memória. Estes efeitos são preocupantes pois afetam diretamente a saúde e rendimento dos alunos e profissionais que trabalham nestes ambientes. Podendo assim afirmar que é sempre necessário uma avaliação e desenvolvimento de pesquisas de conforto ambiental nos ambientes de ensino, de forma que se possa otimizar as atividades desenvolvidas nesses locais.

\section{REFERÊNCIAS}

BATISTA, J.B.; CARLOTTO, M.S.; COUTINHO, A.S.; PEREIRA, D.A.; AUGUSTO, L.G. O ambiente que adoece: condições ambientais de trabalho do professor do ensino fundamental. Cadernos Saúde Coletiva, v. 18, n. 2, p. 234-242, 2010. 
BATIZ, E.C.; GOEDERT, J.; MORSCH, J.J.; KASMIRSKI-JR, P.; VENSKE, R. Avaliação do conforto térmico no aprendizado: estudo de caso sobre influência na atenção e memória. Produção, v. 19, n. 3, p. 477-488, 2009.

BOURBIA, F.; BOUCHERIBA, F. Impact of street design on urban microclimate for semi arid climate (Constantine). Renewable Energy, v. 35, p. 343-347, 2012.

DUARTE, D.H.S.; SERRA, G.G. Padrões de ocupação do solo e microclimas urbanos na região de clima tropical continental brasileira: correlações e propostas de um indicador. Revista Ambiente Construído, v. 3, n. 2, p. 7-20, 2003.

FRANCO, F. M.; NOGUEIRA, M. C. J. A. Análise microclimática em função do uso e ocupação do solo em Cuiabá-MT. Mercator, Fortaleza, v. 11, n. 26, p. 157-170, 2012.

HOLANDA, A. Roteiro para construir no Nordeste: arquitetura como lugar ameno nos trópicos ensolarados. 48 f. Dissertação (Mestrado em Desenvolvimento Urbano)Universidade Federal de Pernambuco, Recife, 1976.

LAMBERTS, R.; GHISI, E.; PAPST, A.L. Desempenho térmico de edificações. Apostila LabEEE, Universidade Federal de Santa Catarina, 3 ed., 2005.

LAMBERTS, R., XAVIER, A.A., GOULART, S.; VECCHI, R.D. Conforto e stress térmico. LabEEE, Universidade Federal de Santa Catarina, 2011.

LENGEN, J. V. Manual do Arquiteto Descalço. Rio de Janeiro, 2004.

MILlS, G.; CLEUGH, H.; EMMANUEL, R.; ENDLICHER, W.; ERELlE, E.; MCGRANAHAN, G.NG.E.; NICKSON, A.; ROSENTHAL, J.; STEEMER, K. Climate Information for Improved Planning and Management of Mega Cities (Needs Perspective). Procedia Environmental Sciences, v. 1, n. 1, p. 228-246, 2010.

PAULA, R.Z.R. A influência da vegetação no conforto térmico do ambiente construído. 119 f. Tese (Doutorado em Engenharia Civil, Arquitetura e Urbanismo)-Universidade Estadual de Campinas, Campinas, 2004. 
PIZARRO, P.R. Estudo das variáveis do conforto térmico e luminoso em ambientes escolares. 178 f. Dissertação (Mestrado em Desenho Industrial)-Universidade Estadual Paulista, Bauru, 2005.

RUAS, A.C.; LABAKI, L.C. Ventilação do ambiente e conforto térmico. VI Encontro Nacional e III Encontro sobre Conforto no Ambiente Construído. São Pedro, São Paulo. 8p. 2001.

SANTOS, J.S. Campo térmico urbano e a sua relação com o uso e cobertura do solo em uma cidade tropical úmida. $108 \mathrm{f}$. Tese (Doutorado em Recursos Naturais). Universidade Federal de Campina Grande, Campina Grande, 2011.

SHAMS, J. C. A.; GIACOMELI, D. C.; SUCOMINE, N. M. Emprego da arborização na melhoria do conforto térmico nos espaços livres públicos. REVSBAU, Piracicaba-SP, v. 4, n. 4, p. 1-16, 2009. 